\title{
EL CASO HONECKER, EL INTERÉS NACIONAL Y LA POLÍTICA EXTERIOR DE CHILE CONTORNOS Y TRASFONDO DE UN PROBLEMA “INTERMÉSTICO”
}

\author{
Ivan Witker
}

\begin{abstract}
Este trabajo analiza la llegada del depuesto Presidente del Consejo de Estado de la República Democrática Alemana Erich Honecker a la embajada chilena en Moscú, sus circunstancias, motivos y consecuencias. Primeramente se constata la existencia de un problema inédito para la diplomacia chilena. Luego se indaga sobre el "poder invisible” que movió la espiral de fidelidades emocionales mutuas tan característica del acercamiento Chile-RDA. Se examina un conjunto de temas políticos e históricos que ayudan a explicar el problema, como los submundos políticos chilenos, la "diplomacia lateral” de la RDA, las relaciones diplomáticas entre los dos países durante el gobierno de Allende, el asilo masivo a chilenos y la confrontación de éstos con el socialismo real, el interés de la Stasi por los problemas chilenos y otros. Concluye preguntándose a quién sirvió recibir a Honecker en la legación chilena.
\end{abstract}

Ivan WitKer. Ph.D. por la Universidad Carlos IV, Praga, República Checa. Director de la Cátedra de Relaciones Internacionales de la Academia Nacional de Estudios Políticos y Estratégicos (ANEPE), profesor del Doctorado en Estudios Americanos de IDEA/USACH y profesor de cultura latinoamericana en la Universidad de los Andes, Santiago. 


\section{Habemus problemam}

\section{工 a decisión del destituido Presidente del Consejo de Estado de la} República Democrática Alemana (RDA) de solicitar asilo en la embajada chilena en Moscú constituye uno de los episodios más singulares de la historia diplomática de Chile. Nunca antes el país había estado sometido a una tensión tan gravitante respecto a un asunto global. Jamás se había sentido tan expuesto y tan cerca del vértigo de aquello que Joseph Nye denomina soft power. Desde la lejanía geográfica, al círculo decisor chileno le resultaba casi inescrutable el abanico de posibilidades que tendrían Alemania y Rusia para ejercer su poder (no militar) para influir en esta delicada materia de la política mundial, perteneciente, para ambos países, a lo más íntimo de su propio interés nacional.

Una extraña atmósfera fue apoderándose de la vida política nacional a medida que pasaban los días. Por un lado, estaba un pesado asunto doméstico, pues un importante sector de la coalición gobernante decía sentirse obligado a practicar un acto de fidelidad emocional - Nibelungentreue - o sea, a devolverle la mano a quien décadas atrás había mostrado una actitud generosa para con ellos. Por otro, el resto de la sociedad percibía una circunstancia compleja, que combinaba elementos tan disímiles como pudiesen ser el típico sentimiento chileno de humanitarismo con quien cae en desgracia y una buena dosis de pánico ante la idea de adentrarse por laberintos desconocidos y estar sometido a fuerzas remotas. El gran temor que se advertía en el entorno presidencial era el impacto que este problema pudiese tener en un proceso de transición que aún no llegaba a la etapa de consolidación.

Sin embargo estos temores no constituían novedad alguna. La historia de la política exterior de Chile registra evidentes dificultades del círculo decisor para tomar posición respecto a los temas globales más conflictivos. En el pasado lejano fue ante las dos guerras mundiales y luego ante la crisis de los misiles en Cuba; en el pasado reciente ante la intervención norteamericana en Irak. En todas ellas, el círculo decisor creyó interpretar fielmente a la sociedad chilena dilatando decisiones, forzando la neutralidad, evitando involucrarse. En esta actitud siempre estuvo subyacente la percepción de que, ante coyunturas tan delicadas y sujetas a controles tan lejanos como ajenos, cualquier paso en falso o acción apresurada sólo traería perjuicios al país.

Esta aversión chilena por los grandes eventos internacionales, que exigen definiciones tan taxativas, podría explicarse si se tiene en consideración que éste es uno de los países donde más fuerza tiene lo que algunos 
autores, como Donald Kagan, denominan el primado de la política doméstica en los asuntos exteriores. Por razones diversas, la política exterior chilena ha sido desde siempre un genuino reflejo de la correlación de fuerzas políticas internas que se da en el momento preciso de una coyuntura internacional demandante. Lo interno condiciona lo externo. O, para ser más precisos, los factores domésticos en Chile se entrecruzan con las variables externas de manera mucho más activa e intensa que en otro país de tamaño y capacidades similares.

\section{Chile y la RDA: arcana imperii}

La irrupción de la llamada República Democrática Alemana en la arena internacional, a partir de la realidad post Segunda Guerra Mundial, fue un proceso lento y pedregoso. Hasta fines de los 60 vivió un evidente aislamiento político, que la mantuvo excluida del sistema de Naciones Unidas, con pocas representaciones diplomáticas en el extranjero, bajo nivel de diversificación de su comercio exterior y escasa capacidad de diálogo político internacional. Berlín oriental vivía mediatizado casi enteramente por Moscú ${ }^{1}$.

Dicho aislamiento se debió a la escasa gravitación política, relativa insignificancia económica y necesidades geoestratégicas de las superpotencias, como también a los efectos de la llamada doctrina Hallstein², uno de los pilares de la política exterior de la República Federal Alemana en los 50 y 60. Por acción de estos cuatro elementos que se potenciaban entre sí, la "otra Alemania”, surgida en la antigua zona de ocupación soviética, se

${ }^{1}$ La RDA fue fundada el 7 de octubre de 1949. Hasta septiembre de 1955 su estatus jurídico fue de dependencia total de la URSS. El 20 de septiembre de ese año (tras la constitución de la OTAN y del Pacto de Varsovia), la RDA recibió formalmente su soberanía de manos del Kremlin, lo que se tradujo en una reducción formal de la dependencia, pues de facto siguió siendo una cuasi colonia soviética.

${ }^{2}$ La "doctrina Hallstein" es la denominación de un principio vigente en la formulación de política exterior de la República Federal Alemana (RFA) desde 1955 hasta comienzos de los 70 y que reclamaba para la RFA la representación unívoca del Estado alemán en el sistema internacional (Alleinvertretungsanspruch). Este principio formulado por el entonces secretario de Estado del Ministerio de Relaciones Exteriores, Walter Hallstein, advertía a aquellos países que reconocieran diplomáticamente a la República Democrática Alemana (RDA) con el rompimiento de relaciones. Así, por ejemplo, cuando Cuba fue el primer país del hemisferio que reconoció formalmente a la RDA el 12 de enero de 1963, la RFA reaccionó rompiendo relaciones con la isla caribeña. Anteriormente, en 1957 había sucedido lo mismo con Yugoslavia. La doctrina Hallstein perdió fuerza paulatinamente con el inicio de la Ostpolitik de Willy Brandt. 
mantuvo por muchos años tanto para la opinión pública como para la vida diplomática internacional en una suerte de "lado oscuro".

Estas fuertes restricciones llevaron a Berlín oriental a desplegar una política exterior diferenciada en una diplomacia directa o tradicional y otra "lateral”. La primera focalizada exclusivamente en las siguientes áreas:

a) Relaciones políticas, económicas, militares y culturales privilegiadas con la Unión Soviética y demás países integrantes del Pacto de Varsovia y el Tratado de Ayuda Mutua Económica (COMECON), considerados para todos los efectos como aliados.

b) Relaciones con los otros países comunistas del orbe: China, Corea del Norte, Albania, Cuba y Vietnam del Norte.

c) Relaciones con países "amigos", fundamentalmente adherentes al llamado socialismo panárabe, que durante las décadas del 50 y 60 buscaron apoyo (económico y militar) en la URSS: Siria, Irak, Egipto, Libia, Argelia.

La segunda, la diplomacia lateral, fue un mecanismo ideado por el entonces jefe de Estado Walter Ulbricht destinado a hacer más llevadero su aislamiento internacional y orientado a los llamados países del Tercer Mundo, especialmente los latinoamericanos. Ésta consistió en crear institutos de amistad binacional y sociedades culturales, convenientemente monitoreados desde Berlín oriental a través de diversos institutos de solidaridad que eran parte de su dendrítica estructura estatal ${ }^{3}$, buscando impulsar relaciones en un plano societal. Para coordinar la diplomacia lateral con los países latinoamericanos se creó en Berlín oriental a fines de los 50 la Sociedad de Amistad Germano-Latinoamericana, la cual se ocupó de buscar afinidades con universidades, intelectuales, parlamentarios y las ONG de la región.

Las actividades de esta diplomacia lateral potenciaron significativamente las campañas de solidaridad y ayuda a partidos comunistas y socialistas latinoamericanos, así como a sindicatos y federaciones estudian-

${ }^{3}$ El sistema de organización de la RDA tenía en su cúspide al Buró Político del Partido Socialista Unificado Alemán (PSUA), desde donde se controlaban los diversos órganos de poder en línea jerárquica hacia abajo. En el plano externo, la estructura partía por el Departamento Internacional del Comité Central (que reportaba al Buró Político), seguían más abajo, pero en un mismo nivel horizontal, el Ministerio de Asuntos Exteriores, la Comisión Estatal de Planificación y el Ministerio de Defensa. Cada uno conectado por vías indirectas y separadas entre sí con el Ministerio de Seguridad del Estado (Staatssicherheitsministerium), la popular Stasi, que reportaba sólo al Secretario General del PSUA. Los institutos de solidaridad dependían del Ministerio de Asuntos Exteriores, pero estaban integrados por personal periférico de la Stasi o directamente por agentes del servicio. 
tiles. Esta labor, marginal pero persistente, le permitió ir identificando a personeros de diversos ámbitos del quehacer nacional de cada país que pudiesen simpatizar con las ideas socialistas y, por ende, susceptibles de ser invitados a colaborar con esta Alemania pro soviética. No es de extrañar entonces que, en este contexto, Pablo Neruda y Delia del Carril hayan sido invitados especiales al Festival de la Juventud organizado por la RDA en 1953. Por esta vía se gestó con los años una vasta red de entidades conectadas a entidades mayores, como la Organización Mundial por la Paz, Unión Internacional de Estudiantes, Federación Mundial de Juventudes Democráticas, Federación Sindical Mundial y otras que actuaban como actores no estatales al servicio de los países pro soviéticos.

Por su parte, los gobiernos chilenos inmediatamente posteriores a la Segunda Guerra Mundial no expresaron en momento alguno interés por acercarse a esta Alemania sui generis. Ello no sólo porque las relaciones con la Alemania Federal constituyeron un elemento orientador de las relaciones del país con el continente europeo, sino porque la RDA resultaba del todo exótica a los intereses de la clase política chilena y, desde luego, una potencial fuente de peligros por los efectos de la doctrina Hallstein ${ }^{4}$. Por lo tanto, el interés por la RDA en los 50 fue en Chile una exclusividad de los partidos Comunista y Socialista (principalmente del primero) y una multitud de ONG y agrupaciones culturales periféricas a ambos. En este contexto, y

\footnotetext{
${ }^{4}$ Respecto a la influencia de la doctrina Hallstein en los países latinoamericanos, Krämer recuerda que durante la visita del Presidente del Bundestag (RFA) a Brasil en 1959, éste señaló: "lamentablemente se romperían nuestras relaciones con el Brasil, si este país las estableciese con la RDA”. Así reaccionó ante la idea del Presidente Janio Quadros de acercarse a la RDA. El propicio ambiente que reinaba en esos años en Brasil hizo pensar a los dirigentes de la RDA en la posibilidad de instalar un representante especial para América Latina. Incluso, una delegación parlamentaria brasileña, dirigida por el entonces influyente legislador Joao Dantas, viajó a Berlín oriental en 1961 (Krämer, 1995, p. 184). Entretanto, parlamentarios de la Volkskammer de la RDA viajaron a Bogotá, Colombia, en 1965 y una delegación encabezada por el importante dirigente Gerald Götting visitó al año siguiente Colombia, Ecuador y Chile. Producto de estos contactos, en 1968, se inauguró el Planetario Carl Zeiss de Bogotá construido íntegramente en la ciudad de Jena, RDA. Igualmente este tipo de relación avanzó rápido con México, país donde la RDA instaló una pequeña oficina comercial en 1967. Al año siguiente, la RDA tuvo una muy exitosa participación en las olimpíadas celebradas en ese país, ocasión que el gobierno germanooriental aprovechó para organizar exposiciones culturales; en ese marco consiguió firmar sendos acuerdos entre la UNAM y la Universidad de Xalapa con la Universidad Humboldt de Berlín y la Technische Universität Dresden, respectivamente. A partir de estos importantes episodios, los alemanes orientales comenzaron a familiarizarse con la literatura latinoamericana, pues editoriales de la RDA compraron los derechos para publicar ciertas obras literarias de interés político: Gabriel García Márquez, Volodia Teitelboim, Carlos Fuentes y Julio Cortázar. Ver Witker (1988), pp. 2 y 3.
} 
casi de forma coetánea con otros países latinoamericanos, surgió en Chile una Sociedad de Amistad Chile-RDA, dirigida desde fines de los 50 por el político socialista Osvaldo Puccio Giesen, un comerciante importador de productos alemanes que, por ese entonces, ya se desempeñaba como secretario particular del senador Salvador Allende ${ }^{5}$. A fines de los 60, la RDA abrió una pequeña oficina comercial, dirigida por Harry Spindler, quien, luego de la apertura de las relaciones diplomáticas, alcanzó a ser promovido a embajador. Puccio Giesen relata en sus memorias la excelente relación que estableció con Spindler y destaca la visita de Werner Kirchhoff y Friedel Trappen como delegados del PSUA al congreso del Partido Socialista en 1967 celebrado en Chillán y que marcó un hito en el desarrollo de ese partido ${ }^{6}$. Trappen asumiría más tarde como embajador en reemplazo de Spindler y permanecería en ese cargo hasta septiembre de $1973^{7}$.

La victoria de la Unidad Popular en Chile sorprendió gratamente a Berlín oriental, situación que no había sido prevista ni por la diplomacia ni por su famoso servicio de inteligencia, la Stasi. El impacto internacional que tendría este hecho fue debatido largamente por el Buró Político del PSUA el 20 de octubre de 1970. Su resolución fue enviar una delegación bicéfala, encabezada por el parlamentario Otto Gosche, que tendría a su cargo cuestiones protocolares, y por Kurt Seibt, Presidente del Comité de Solidaridad Internacional, que sondearía el ambiente político en Santiago. Gosche aprovecharía de visitar también Bolivia, Perú y Colombia.

Gracias a la influencia de Puccio Giesen, Allende tuvo un trato muy deferente con los enviados de Berlín oriental y les ofreció avanzar pronto en el establecimiento de relaciones diplomáticas, lo cual se materializó el 16 de marzo de 1971 mediante un protocolo firmado por Alcides Leal, por la parte chilena, y Otto Winzer, por la germanooriental ${ }^{8}$. La doctrina Hallstein se

${ }^{5}$ Codueño junto a Allende y otras personas de la Comercial Arauco. Ver Puccio (1985), p. 166.

${ }^{6}$ Ibídem, p. 168. Según Puccio Giesen, la visita de ambos consolidó los vínculos del Partido Socialista con la RDA.

${ }^{7}$ Sin embargo, Trappen fue derivando paulatinamente a la "diplomacia de carrera”, por lo que entre 1971 y 1973 el "jefe político” de la misión diplomática de la RDA en Santiago fue Karlheinz Möbus. La preponderancia de este último quedó de manifiesto más tarde al ser el coordinador de la ayuda a los exiliados chilenos en la RDA.

${ }^{8}$ Durante estas conversaciones preliminares, el nuevo gobierno chileno le señaló a la parte alemana su deseo de abrir mercados euroorientales al cobre chileno. A fines de 1971 fue conformado un Comité de Colaboración Científica, Económica y Técnica. Esta información fue extraída de dos trabajos de Krämer, quien a su vez se remite a las actas y protocolos oficiales de la RDA que se encuentran abiertos al público. Ver Krämer (2003), p. 2. 
pondría a prueba en un punto bastante alejado de aquellos neurálgicos del conflicto global.

Bonn optó por no desatender este inédito proceso en los confines del mundo, especialmente por sus posibles consecuencias en el tímido proceso alemán federal de apertura al Este, inaugurado con las elecciones de 1966 y que tropezaba con innumerables dificultades tanto internas como externas ${ }^{9}$. Por ello, la evolución de la política chilena había comenzado a ser objeto de un seguimiento más acucioso de parte de Bonn desde que asumiera Eduardo Frei Montalva, un hombre con muy buenos vínculos con la gobernante Unión Demócrata Cristiana (CDU) y que se había preocupado de fomentar los contactos con toda Europa occidental. Entretanto, los socialdemócratas alemanes, liderados por el carismático Willy Brandt, habían accedido al poder en 1970 teniendo como propuesta programática central una fuerte reorientación de la política exterior germanofederal, y acelerando la apertura hacia el Este. El destrabamiento de las relaciones de la RFA con la URSS, la RDA y todo el bloque pro soviético impactó positivamente en el afianzamiento de la paz europea y es conocido al interior de la disciplina de las relaciones internacionales como Ostpolitik.

Por lo tanto, cuando Chile y la RDA acreditaron sus embajadores, Bonn optó, en forma inédita, por respetar la decisión chilena. El clima internacional estaba cambiando y la doctrina Hallstein empezaba a quedar definitivamente atrás; con esto se acercaba rauda la hora del ingreso de ambas Alemanias a la Organización de Naciones Unidas, que se materializaría el 18 de agosto de $1973^{10}$.

Pari passu, en Berlín oriental también se vivían cambios de envergadura. El 3 de mayo de 1971, Ulbricht había sido desplazado de su cargo de Secretario General del PSUA por un grupo de dirigentes más jóvenes, menos asociado a la era staliniana, encabezado por Erich Honecker ${ }^{11}$. Con él

${ }^{9}$ Ese mismo año se intentó infructuosamente establecer relaciones diplomáticas con Rumania. Brandt consiguió suscribir importantes tratados con Polonia y la URSS y en 1972 uno con la RDA, denominado Grundlagenvertrag, el cual permitiría al año siguiente el ingreso de ambas Alemanias a Naciones Unidas.

${ }^{10}$ En 1980, la tendencia al amplio reconocimiento internacional tuvo un fuerte impulso al ser elegida la RDA miembro no permanente, por dos años, del Consejo de Seguridad de la ONU.

${ }^{11}$ Otras figuras centrales del "cuadrillazo" en contra de Ulbricht fueron Willy Stoph, quien asumió como Primer Ministro; Hermann Axen, quien pasó a controlar las relaciones externas; Günter Mittag, una suerte de superministro de facto de Economía; Heinz Kessler, que ocupó la cartera de Defensa, y Erich Mielke, jefe de la Stasi desde los 50. Honecker nació el 25 de agosto de 1912 en la localidad de Wiebelskirchen, Saarland, en el seno de una familia minera. En su juventud ingresa al grupo ultraizquierdista Espartaco y luego a la Juventud Comunista. Entre 1930 y 1931 permanece en Moscú estudiando 
dominando la escena política interna, la RDA declaró su ingreso a un estadio nuevo de desarrollo del socialismo, denominado "sociedad socialista desarrollada” (entwickelte sozialistische Gesellschaft), caracterizada por un interés más efectivo por integrarse, al menos parcialmente, a la economía mundial y por alcanzar una interlocución política propia -i. e. menos mediatizada por Moscú - con el resto del mundo. Este objetivo pasaba por superar la diplomacia lateral, diversificar sus relaciones diplomáticas y, desde luego — como virtual cereza del postre- ingresar a Naciones Unidas. Un componente central de esta nueva política fue la exitosa ofensiva en América Latina. Para darle fundamento a este importante giro de la política exterior germanooriental, Honecker, Axen y Mittag promovieron un importante debate al interior de las universidades de la RDA sobre "el carácter del capitalismo en América Latina” con la finalidad, como dice Krämer, de conducir un enfoque político más diferenciado hacia la región. En este proceso destacaron Manfred Kossok y Eberhard Hackethal, quienes instalaron un gravitante Departamento de Estudios de América Latina en la Karl-Marx-Universität de Leipzig y se transformaron en los más importantes latinoamericanistas germanoorientales.

La visita del canciller de Allende, Clodomiro Almeyda, a mediados de 1971 a Berlín oriental fue vista por sus anfitriones como el mayor de los halagos. Durante su estadía, Almeyda les aseguró el resuelto apoyo chileno al ingreso de la RDA a la ONU y a la Organización Mundial de la Salud (cuya postulación la diplomacia germanooriental había formalizado con semanas de antelación a la visita). Inmediatamente después del viaje del canciller viajaron a diversas ciudades de la RDA el conjunto folklórico Quilapayún y Víctor Jara, cuyas multitudinarias presentaciones se convirtieron en verdaderos hitos culturales —especialmente para las generaciones más jóvenes- que oxigenaron y ventilaron la hasta ese momento lúgubre atmósfera cultural de la RDA. Impacto aún mayor tuvo el posterior viaje de V. Jara junto al excéntrico "cowboy del socialismo" residente en Santiago, Dean Reed ${ }^{12}$. Según Krämer, Chile le comenzó a entregar a la uniforme

en diversas escuelas del PCUS. En 1947 se casa con la dirigente comunista alemana Edith Baumann, con la que tiene una hija, Erika. En 1955 se divorcia de ella en medio de un escándalo en el que interviene el propio Walter Ulbricht, y contrae matrimonio con una funcionaria comunista 18 años menor que él, Margot Feist, con quien había tenido una hija (Sonia) en 1951. Feist fue luego promovida a ministra de Educación y Cultura de la RDA.

${ }^{12}$ En esta relación cultural del Chile de la UP con la RDA tuvo un papel tan importante como curioso este popular crooner norteamericano de los 60, quien el 1 de septiembre de 1970 procedió a lavar una bandera norteamericana en el frontis de la embajada de su país en Santiago protestando contra la guerra en Vietnam y apoyando la 
sociedad gemanooriental ciertos "matices exóticos" (exotische Nuancen) $)^{13}$. Para cerrar el virtuoso círculo de 1971, el Secretario General del Partido Comunista, Luis Corvalán, fue recibido por Honecker a fines de ese año con honores de cuasi jefe de Estado, ocasión que aprovechó para entregarle a Chile un crédito de US\$ 15 millones.

En enero de 1972, el Partido Comunista chileno celebró masivamente el $50^{\circ}$ aniversario de su fundación. La delegación de la RDA estuvo presidida por un muy influyente miembro del Buró Político del Partido Socialista Unificado de Alemania, Paul Werner ${ }^{14}$. Durante su visita se firmaron dos acuerdos universitarios, uno entre la Technische Universität Dresden con la Universidad Técnica del Estado y otro entre la Karl-Marx-Universität y la Universidad de Chile. Werner hizo entrega, además, de una nueva ayuda económica al "proceso revolucionario", esta vez de 7 millones de dólares.

1972 fue el annus mirabilis de la RDA. A partir de la visita de Werner, la embajada germanooriental en Santiago se transformó en una verdadera punta de lanza de la más grande ofensiva diplomática de la RDA en América Latina (probablemente el más grande emprendimiento diplomático de la RDA hasta ese momento). Ese mismo año abre relaciones con Uruguay y Perú. Desde enero de 1973 las inaugura sucesivamente con Costa Rica, Colombia, Guyana, México, Argentina, Ecuador, Bolivia y Brasil. Para los años inmediatamente siguientes quedan Panamá, Jamaica, Nicaragua y

“liberación” de los pueblos del Tercer Mundo. Tras sus duras declaraciones contra Washington, se integró a la campaña presidencial de Salvador Allende y fue uno de sus invitados especiales a la transmisión del mando. Reed trabó fuerte amistad con Víctor Jara y recorrió con él varios países comunistas en 1972. Se asiló en la RDA al año siguiente. Este excéntrico baladista norteamericano fue visto por las autoridades de la RDA como pieza útil en su diseño de oxigenación relativa de la vida cultural juvenil germanooriental. En 1977 filmó allí (y parcialmente en Bulgaria) la película “El Cantor” dedicada a Víctor Jara. Dean Reed ingresó a Chile en agosto de 1983 y actuó en diversas federaciones estudiantiles y sindicatos; fue expulsado por el gobierno militar. En 1986, víctima de una profunda crisis existencial, se suicidó ahogándose en el lago Zeuthener, cerca de Berlín. Las circunstancias de su muerte nunca fueron aclaradas por el régimen de Honecker, el cual lo presentó como “un trágico accidente”, aunque después de 1989 han surgido numerosas hipótesis (muerto por la Stasi después de manifestar su deseo de regresar a EE.UU., muerto por el Mossad por su creciente involucramiento en la causa palestina, etc.). Sus restos descansan aún (2006) en el cementerio berlinés de Waldfriedhof Rauchfangwerder.

${ }^{13}$ Krämer (2003), p. 1.

${ }^{14}$ En el verano de 1960, este funcionario había cumplido una misión similar en Cuba. Tras su viaje a La Habana y larga entrevista con Fidel Castro, Werner emitió un informe favorable y el 13 de septiembre de ese año el Buró Político elaboró un documento llamado "Directiva sobre el Desarrollo de las Relaciones con la República de Cuba”, que dio comienzo a las relaciones entre ambos países. Ver Krämer (1995), p. 185. 
Grenada. Esta ofensiva en América Latina fue seguida por otra similar a mediados de los 70 en África, con Angola y Etiopía como principales puntos de apoyo.

Pese a que resultaría ingenuo suponer que esta ofensiva de la RDA en América Latina no actuaba sobre palancas ideológicas, y que por ende no instigaba movimientos revolucionarios, los antecedentes disponibles indican que aquello fue secundario y que el objetivo central fue reforzar el principio de la estatalidad propia de la RDA. Su fundamento fue esencialmente pragmático; su punto de partida, la ya agotada diplomacia lateral. El mejor indicador de ello es que la expansión de sus lazos con el resto del mundo se aceleró vertiginosamente después de la apertura hacia América Latina. En el cenit de su reconocimiento internacional, a comienzos de los 80, la RDA llegó a tener 123 embajadas repartidas por todos los continentes. En 1981, Honecker es invitado a Japón y se produce la primera cita cumbre interalemana entre el canciller Helmut Schmidt y Honecker en la localidad de Werbellinensee; dos años más tarde, Honecker recibe en Berlín oriental al líder ultraderechista Franz Josef Strauss, quien había ayudado en ese entonces a la RDA a obtener créditos de la banca alemana occidental. En 1984 recibió la visita oficial de los premieres canadiense Pierre Elliot Trudeau, griego Andreas Papandreu, sueco Olaf Palme e italiano Bettino Craxi, y al año siguiente viaja a Italia (primera visita a un país de la OTAN) y al Vaticano. En 1987, Honecker visita por primera vez la RFA (su natal Saarland, Bonn, Düsseldorf, Wüppertal, Essen, Munich y la ciudad donde nació Marx, Trier). Al año siguiente, visita Francia ${ }^{15}$. El propio Honecker lo fundamentó con claridad meridiana: "en el comercio exterior con países capitalistas habrá que ampliar progresivamente el margen político-comercial y seguir consolidando la inviolabilidad de la RDA en el frente económico"16.

Por lo tanto, el factor chileno debe entenderse como germen de esta muy exitosa ofensiva. Chile hizo sentirse a la elite germanooriental parte orgánica del mundo, un integrante con capacidades propias de interlocución. Chile ayudó al liderazgo que encarnaba Honecker permitiéndole ganar cierta legitimidad ante su propia población, la cual entendía el significado de alcanzar una estatalidad a pesar de las limitaciones que imponían la Guerra

${ }^{15}$ Incluso existen antecedentes del interés de Honecker por avanzar en el reconocimiento mutuo con EE. UU. En enero de 1986, once miembros de la Cámara de Representantes fueron invitados a Berlín oriental y recibidos por Honecker para analizar esta posibilidad. Ver sitio www.ddr-geschichte.de en internet. En los datos biográficos de Honecker que entrega la enciclopedia virtual wikipedia en alemán se confirman los esfuerzos en este sentido, que señalan que una posible llave ("Türöffner”) podría haber sido el Congreso Mundial Judío; de.wikipedia.org

${ }^{16}$ Citado en Witker (1988), I, p. 5. 
Fría y especialmente el contexto interalemán. Chile se instaló en lo más íntimo de los secretos de Estado de la RDA. Ello explica el afecto y respeto que fue sintiendo de manera creciente el círculo decisor germanooriental por este lejano país.

Una mirada etiológica no podría sino valorar la osadía (e idealismo) de la diplomacia chilena de entonces de oponerse a la doctrina Hallstein, sin que hubiese de por medio un elemento de transacción con Bonn, ni siquiera una petición expresa o indirecta a través de intermediarios. En Berlín oriental se valoró en su justa medida el impulso idealista de la administración Allende y se le sacó el máximo provecho posible. Es muy probable que en el acercamiento chileno a la RDA hayan intervenido sinérgicamente variables fortuitas, como la cercanía de Puccio Giesen con dirigentes comunistas alemanes y la formación escolar de Almeyda (un agradecido alumno del Liceo Alemán) y su posterior adhesión al marxismo, donde la gran admiración personal e intelectual que éste sentía por Marx llegaba a extremos tales que una de sus obsesiones de juventud era visitar Trier (la ciudad donde nació Marx). Es muy probable que en el desarrollo de los sentimientos de Almeyda respecto a Marx (y el marxismo) haya jugado un papel no menor su especial germanofilia, heredada de su padre, Manuel Almeyda Arroyo, un ingeniero civil que tras un viaje a Europa, luego de finalizar sus estudios universitarios, no ocultaba su absoluta admiración por las ciencias físicas y matemáticas de la Alemania imperial reiterando una y otra vez a su familia el sueño de irse a trabajar a la Technische Universität Dresden, con la que mantuvo fluidos contactos académicos ${ }^{17}$.

Por estas razones resulta comprensible la actitud tan efusiva adoptada por la dirigencia de Berlín oriental tras el 11 de septiembre de 1973. Tan sólo una semana después, Berlín oriental resuelve interrumpir las relaciones diplomáticas con el gobierno de Augusto Pinochet ${ }^{18}$ y dar asilo a cerca de dos mil militantes izquierdistas chilenos que llegan a ese país por diversas vías, algunas legales, otras clandestinas. Pero además opta por involucrarse en la espectacular operación de rescate del Secretario General del Partido Socialista chileno, Carlos Altamirano, a través de la Stasi, y ponerlo vivo y a salvo en Europa. Lo primero puede entenderse como una vuelta de mano en el plano de las emociones. Una retribución a quienes sin razones aparentes (más allá del profundo idealismo con que miraban los asuntos internacionales) se habían esmerado por hacerle un lugar a la RDA en el mundo. Lo segundo, claramente para elevar el prestigio internacional de las singulares

${ }^{17}$ Una visión íntima de Almeyda respecto a la RDA, en sus memorias, pp. 9293.

\footnotetext{
${ }^{18}$ Rumania pasó a representar los intereses diplomáticos de la RDA en Santiago.
} 
capacidades operativas de su servicio de inteligencia ${ }^{19}$. En suma, reacción realista a impulsos idealistas.

Markus Wolf, el mítico "hombre sin rostro" que encabezaba la inteligencia germanooriental, asegura en sus memorias que su servicio no tenía una representación numerosa — como la cubana — en Santiago en septiembre de 1973 y que sus acciones las canalizaban a través de "sólo" dos agentes residentes ${ }^{20}$. También subraya que a través de sus agentes infiltrados en la inteligencia germanofederal sabían de la inminencia del golpe militar (además se queja de que el Secretario General del PC chileno, Luis Corvalán, pese a ser advertido, ignoró la información). Wolf entrega también el más pormenorizado relato de cómo la Stasi sacó clandestinamente de Chile al Secretario General del Partido Socialista, Carlos Altamirano (alias compañero Roberto). "Realizamos una de las misiones de rescate más complicadas de todas las que habíamos realizado hasta entonces. Un equipo de nuestros mejores funcionarios fue despachado para verificar la permeabilidad de los controles de inmigración en los aeropuertos chilenos, en el puerto de Valparaíso y en los pasos de carretera hacia Argentina"21. Altamirano y otras personas fueron sacadas del país en una compleja operación que incluyó barcos de carga y transportes terrestres en la cual tomaron parte 14 agentes de la Stasi. Tal impacto tuvo esta operación de la Stasi que meses más tarde la KGB planificó una que podría haber sido aún más espectacular, rescatar a Corvalán de la prisión en isla Dawson a través de comandos anfibios con base en un submarino en alta mar. El propio Corvalán, citando al general Tolstikov, la relata en uno de sus libros de memorias. Problemas técnicos impidieron ejecutarla y sólo en ese momento el Kremlin optó por negociar por intermedio de los embajadores de la URSS y Chile en la ONU el canje de Corvalán por el disidente soviético Vladimir Bukovsky²2.

${ }^{19}$ El Ministerio de Seguridad del Estado (Staatssicherheitsministerium) fue fundado el 8 de febrero de 1952. Estuvo dirigido desde 1957 hasta 1989 por Erich Mielke y realizaba tanto las tareas de inteligencia interna como externa y la contrainteligencia. Las novelescas acciones operativas (sistemática infiltración de gobiernos y ejércitos occidentales por medio de espías "Romeo” y "Julieta”) estuvieron a cargo de la Administración Central de Espionaje (Hauptverwaltung Aufklärung), encabezada por el ya mítico Markus Wolf. Este departamento de la Stasi fue formado en 1953 y tuvo diversas denominaciones hasta alcanzar la definitiva en 1956. Datos sobre el servicio de inteligencia de la RDA, en Roewer (2003), p. 501, y en las memorias de Wolf (1997).

${ }^{20}$ Uno de ellos fue identificado por reporteros chilenos como Paul Ruschin. Ver Ortega (2001).

${ }^{21}$ Wolf (1997), p. 350.

${ }^{22}$ Corvalán (1997), p. 234. El acuerdo lo gestionaron los embajadores de Chile y la URSS ante la ONU, Manuel Trucco y Yuri Vorontsov, respectivamente, actuando como garantes Harry Schlaudeman, secretario adjunto del Departamento de Estado para Asuntos Interamericanos, y William Hyland, del Consejo de Seguridad de EE. UU. Ver Corvalán (1993), p. 53. 
Luego, Honecker entregó cuantiosos recursos financieros y materiales para que los principales partidos que en ese entonces se oponían a Pinochet tuviesen bases de apoyo. Para atender los problemas de inserción de los millares de refugiados repartidos por todas las ciudades germanoorientales creó en la capital una cuasi oficina consular, llamada Chile Antifascista (CHAF) ${ }^{23}$.

Sobre la decisión personal de Honecker de ayudar a los exiliados chilenos, "Mischa", como se conocía a Wolf, escribe: "Después del asesinato de Allende (sic) en 1973 y la campaña del terror contra la izquierda bajo el gobierno del general Pinochet, pudimos emplear a Cuba como vía de escape para los refugiados chilenos. La hija de Erich Honecker estaba casada con un chileno, de modo que Alemania oriental hizo todo lo posible por ayudar a la oposición de ese país. A Honecker le agradaba la idea de que Alemania oriental ofrecía ayuda humanitaria a quienes la necesitaban. Ayudar a Chile y a otros países latinoamericanos donde la izquierda estaba siendo diezmada por los gobiernos militares y de extrema derecha fue también una actitud apreciada por la juventud del Este. No es exagerado afirmar que estas campañas de los años 70 fortalecieron a Alemania oriental, al conferir a mi asediada nación un aura de respetabilidad”24.

Los miles de chilenos que fueron acogidos en ese país se fueron integrando paulatinamente no sólo a la cotidianeidad de los ciudadanos germanoorientales, a sus aspiraciones, sueños y limitaciones, sino también a las realidades políticas y sociales del país. Conocieron de cerca el modus operandi de los órganos de poder en la RDA y lograron por esta vía ubicar su drama grupal en el contexto internacional global. Como toda experiencia vital, algunos se defraudaron con el modelo socialista inmediatamente, otros más tarde, con el paso de los años, y una buena cantidad, nunca, manifestando añoranza incluso a varios lustros de desaparecida la RDA.

Hacia la segunda mitad de la década de los 80, la RDA comenzó a vivir una urgencia que se convertiría en determinante en los años siguientes: diversificar al máximo su comercio en divisas. Nuevamente América Latina apareció en el horizonte. Si en la década anterior América Latina le produjo tantas satisfacciones de tipo político, que le habían permitido dejar atrás el aislamiento, ahora podría ser un buen campo de experimentación

${ }^{23}$ El CHAF cumplía varias funciones. Por un lado, resolver una enorme cantidad de asuntos "consulares" (delitos menores en los cuales se vieron involucrados algunos asilados, fuga hacia Occidente de asilados desilusionados con el socialismo, documentos de identificación para quienes carecían de ellos, gestiones de becas para estudiantes, problemas laborales, etc.), por otro lado, ser un nexo de diálogo político entre el PSUA y los diversos partidos de izquierda chilenos.

${ }^{24}$ Wolf (1997), p. 347. 
como socio comercial. Nuevamente los chilenos allendistas estuvieron prestos a ayudar a la RDA. Por ejemplo, Anselmo Sule y otros líderes del Partido Radical en el exilio habían tendido estrechos vínculos con partidos socialdemócratas latinoamericanos (que habían accedido al gobierno en sus países) e intercedieron ante ellos para que actuasen con receptividad ante las propuestas de la diplomacia oficial germanooriental ${ }^{25}$.

Las necesidades económicas obligaron a la RDA a superar lo que Krämer denomina la lógica del autobloqueo respecto a Chile, la única economía latinoamericana que no aparecía sumida en los graves problemas de deuda externa de la época (la década perdida) y que mostraba signos de florecimiento. Ante esta inesperada realidad, el PSUA elaboró un documento denominado "Medidas para el Restablecimiento de Contactos con Chile", que proponía un acercamiento independientemente de la prolongación o no del gobierno militar. Éste contemplaba reabrir una oficina de intereses en Santiago y comerciar, comprando principalmente cobre a través de intermediarios en Londres. Este paso a la desideologización de los vínculos con América Latina formaba parte de un creciente pragmatismo germanooriental (forzado por las circunstancias adversas) y que incluyó, entre otros, el inédito encuentro de Honecker con el carismático líder de la Unión Social Cristiana, Franz Josef Strauss, y el viaje de Honecker a la RFA, completamente inesperado para Moscú, pues ni siquiera fue informado previamente, como solía ocurrir. Y es que la premura por obtener divisas se fue agudizando de manera paralela a la perestroika, lo que dio paso a un proceso de bifurcación entre los intereses de la RDA y los de la URSS. Un malestar mutuo que acompañó las relaciones bilaterales en el ocaso de estos dos desaparecidos estados socialistas.

En ese contexto, en 1987, el diario de Berlín oriental Junge Welt acreditó un enviado especial al Campeonato Mundial de Fútbol Juvenil realizado en Santiago, ocasión que aprovechó para enviar reportajes positivos y notas sobre la vida y acontecer "en el Chile de Pinochet”. Ese año la RDA ingresó al Tratado Antártico y participó en las reuniones celebradas en Santiago, incluso inauguró la estación científica Georg Foster.

A comienzos de noviembre de 1989 —el annus horribilis de la RDA - aterrizaron en Santiago dos altos funcionarios del Ministerio de Relaciones Exteriores, Helma Chrenko y Reinhold Friedmann. Ambos calificaron de "notable" el desempeño económico del Chile de los 80 y hablaron

${ }^{25}$ En versiones informales, personeros de los partidos Socialista y Comunista chilenos se quejan de la "voracidad" con que esos radicales chilenos asumieron los contactos con Honecker. Ellos mismos contribuyeron creando en México y Venezuela empresas exportadoras de artículos tanto de primera necesidad como suntuarios para Alemania oriental. 
de su propósito de abrir una oficina comercial ${ }^{26}$. Sin embargo, ya a su retorno a Berlín oriental a la semana siguiente, el desplome del régimen comunista y la reunificación alemana parecían tan inminentes como inevitables. El objetivo final de su viaje — volver a ver juntos a Chile y la RDA— se desdibujaría por completo.

La restauración democrática en Chile posibilitó el ascenso al poder de numerosos ex exiliados en la RDA. De los casi dos mil chilenos que vivieron allí, una veintena integró el círculo decisor aylwinista ${ }^{27}$. Ellos fueron quienes protagonizaron una nueva vuelta de mano hacia Honecker, pagando con el otorgamiento de refugio a él y su esposa la última deuda inserta en esta espiral de fidelidades emocionales -Nibelungentreue- que cubrió las relaciones chileno-germanoorientales.

\section{Honecker: Cui bono?}

El problema teórico que plantea este caso se resume en la siguiente interrogante: ¿qué origina un impulso idealista tan fuerte y arrebatador, como este gesto hacia Honecker, si toda política exterior de un país se guía, por su naturaleza misma, según criterios de interés nacional?

La comunidad epistémica de relaciones internacionales en nuestro país ha eludido hasta ahora un debate a fondo acerca de cuáles son las lecturas chilenas del concepto interés nacional, su conceptualización actual hacia comienzos del siglo XXI, su evolución histórica, sus singularidades, sus fundamentos, etc. ${ }^{28}$ Dicha conducta inhibitoria resulta muy

26 "Estamos Dispuestos a Aprender del Capitalismo", entrevista sostenida con Ivan Witker, El Diario, 3 de noviembre de 1989, Santiago.

${ }^{27}$ Una síntesis de sus nombres (Ricardo Núñez, Jorge Arrate, Enrique Correa, Clodomiro Almeyda y otros) aparece en Corvalán (1993), p. 87. El tema de la relación de prominentes exiliados en la RDA fue reflotado parcialmente por la prensa alemana luego del triunfo electoral de Michelle Bachelet (enero, 2006), quien vivió un tiempo en Potsdam. Una breve e interesante nota con apreciaciones sobre la vida de Bachelet en esa ciudad por parte de quien actuó como coordinador del apoyo al exilio chileno, en Möbus (2006) y Widman (2005).

${ }^{28}$ Para las escuelas realistas de los estudios internacionales, interés nacional y poder constituyen las dos nociones epistemológicas fundamentales de la disciplina, cuya delimitación se remonta a autores clásicos como Hans Morgenthau y Kenneth Waltz. Por su parte, Evans y Newnham (1990, p. 344) vinculan el interés nacional a las metas y objetivos que se traza una política exterior y sostienen que este concepto universalizó la vieja noción de razón de Estado, vinculada a Richelieu. Asimismo, la principal revista teórica norteamericana asociada a las corrientes realistas se denomina The National Interest, un cuatrimestral dirigido por Nicolás Gvosdev (editor) y Henry Kissinger (honorary chairman). 
llamativa a propósito de las características inusualmente útiles que tiene este caso para una discusión de tipo conceptual aplicado.

Empero nadie duda que el caso exhibe varias aristas y que en consecuencia es abordable desde diversas disciplinas. Una de ellas, la jurídica. Otra la histórica. Pero igualmente nadie pondría en cuestión que éste fue un tema de naturaleza esencialmente política; así se originó, desarrolló y concluyó. Lo jurídico y lo histórico más bien sirven para contextualizar un análisis político en el ámbito de las relaciones internacionales.

Una primera constatación apunta al hecho de que se trata de una extraordinaria ironía del destino que el máximo dirigente de la RDA, un marxista convencido, un guerrero por antonomasia de la Guerra Fría, recurriese al asilo para eludir la acción de la justicia en su país. Ello porque ni el sistema jurídico de la RDA ni el de ningún país comunista reconocieron jamás esta figura del derecho internacional y, si juzgamos las evidencias empíricas, los pocos casos que se dieron tanto en la RDA como en sus vecinos comunistas fueron obstaculizados con el máximo de rigor (verbigracia: férreo control policial en el perímetro de las embajadas, duras penas aflictivas). Ilustrativa fue la postura asumida por el gobierno del propio Honecker ante el asilo de miles de jóvenes germanoorientales a mediados de 1989 en las embajadas de Alemania federal en Varsovia, Praga y Budapest; en los tres casos, el asilo no fue reconocido, se exigió la devolución de los solicitantes y sólo debido a la evidente debilidad de los socialismos reales en aquel momento y a la sagacidad del ministro Hans-Dietrich Genscher se pudo encontrar una solución satisfactoria. Contrariu sensu, en el apogeo del poder internacional de los socialismos reales tuvo lugar el célebre caso del cardenal primado de Hungría Joszef Mindszenty, quien ingresó a la embajada estadounidense en Budapest en 1956, y a quien se le otorgó salvoconducto para salir al extranjero recién en septiembre de 1971, después de innumerables gestiones en las que intervinieron los Papas Juan XXIII y Paulo VI, así como personalmente el Presidente norteamericano Richard Nixon.

También cabe constatar que Chile nunca antes había estado ante el dilema de aceptar o no una petición de asilo con tanta relevancia política internacional como ocurrió en el de marras. No sólo debía tenerse en consideración la trascendencia misma del solicitante, sino la compleja trama del momento político global; i. e., cambios en la correlación de fuerzas a nivel global y europeo, reunificación alemana, derrumbe de la URSS, surgimiento de Rusia, disolución del marxismo como fuerza aglutinadora a nivel mundial y otros. Por lo tanto, no resulta exagerado sostener que el ingreso de Honecker a la embajada chilena en Moscú puso en tensión a la política exterior 
del país, mantuvo en vilo a las fuerzas políticas oficialistas y obligó a pensar como nunca antes en las sutilezas y vericuetos de la vida diplomática, en los resquicios legales que ofrecían las leyes alemanas, chilenas y rusas. Fue un caso excelso de aquello gris, amorfo y borroso que la teoría de las relaciones internacionales ha denominado interméstico, neologismo construido a partir de "lo internacional” y "lo doméstico".

En consecuencia, para dilucidar la pregunta ¿qué origina un impulso idealista tan fuerte y arrebatador, como este gesto hacia Honecker, si toda política exterior de un país se guía, por su naturaleza misma, según criterios de interés nacional?, se debe caracterizar la política exterior formulada bajo el mandato del Presidente Aylwin.

En aquel entonces, el interés nacional fue entendido - $\mathrm{y}$ no podía ser de otra manera— según el o los paradigmas imperantes en los círculos decisores en un momento específico. Durante el gobierno de Aylwin lo que primó fue un híbrido de transnacionalismo, neoinstitucionalismo, interdependentismo y constructivismo, que posibilitó impulsos idealistas con una frecuencia importante (e inevitable) debido a la naturaleza misma del bloque oficialista, un conglomerado abigarrado, cuyo único spiritus movens era la oposición a un orden existente. Un conglomerado formado por fuerzas que hasta pocos años habían estado alejadas y con fuertes recelos entre sí. Una dinámica de tales características, marcada por una convergencia de voluntades que se disponen a reemplazar un estado de cosas en fase de disolución, no puede sino materializarse en una masa heterogénea de formulaciones que sólo rara vez puede identificar de manera elaborada los imperativos estratégicos emergentes ${ }^{29}$. Ello explica muchos arrebatos idealistas del período, tanto en conductas, en propuestas como en percepciones de los asuntos internacionales. Y es que las fuerzas políticas que convivían en la Concertación sólo podían consensuar en el plano externo la vaga pero aglutinante idea de "reinsertar al país en la comunidad internacional". Reinsertar, porque así se tomaba distancia del ancien régime y se tendía un punto de conexión con el estado de cosas previo al gobierno militar; comunidad porque se esperaba que el Chile democratizado fuese recibido con simpatía y afecto por muchos países. Aquí precisamente radica el idealismo de una buena cantidad de personeros, para quienes la por entonces novedosa diplomacia de cumbres y el firme apego discursivo a las nociones madre de aquellos años — regionalismo abierto y cláusula democrática- serían suficientes para dar un paso histórico e irreversible hacia un mundo nuevo donde los conflictos serían una reminiscencia de tiempos pretéritos.

${ }^{29}$ Ver Witker (2005), p. 53. 
Cuesta, al día de hoy, entender tanta candidez. Especialmente si vemos lo ocurrido con la perspectiva del tiempo (crisis del gas con Argentina, emergencia de los movimientos étnicos en Perú y Bolivia, intromisión de Chávez en todos y cada uno de los asuntos bilaterales más sensibles de la región). Sin embargo, la candidez no debiera extrañar. El Chile de la transición fue parte de ese momento tan dramáticamente optimista que vivió el mundo entero tras la caída del Muro de Berlin y la desaparición de la Unión Soviética.

Por eso, pese a que en el círculo decisor aylwinista se evitaba aceptar de forma explícita y abierta la hipótesis de trabajo de Francis Fukuyama, popular por aquellos años, de que democracia y mercado formaban una díada que llevaría a las naciones a dejar atrás la historia (en el sentido hegeliano), se aceptaba implícitamente que algo de verdad había en aquello. Lo lamentable era que el concepto libre mercado se asociaba a las profundas reformas aplicadas por el gobierno militar, lo que generaba un ruido tan disfuncional como inaceptable. Por ello, los principales líderes de opinión de la Concertación recurrían a ejercicios retóricos de diversa intensidad haciendo referencias elípticas e implícitas al libre mercado (como si éste fuese parte natural del paisaje), y preferían poner énfasis en la centralidad de la democracia para resolver cuestiones específicas. Esta cautela conceptual también tenía explicación en el hecho que al círculo decisor aylwinista le intrigaba de sobremanera el impacto que podría tener en los sectores más izquierdistas de la coalición de gobierno el derrumbe del socialismo real. Así se entiende la extrema — y a ratos enervante — cautela con que Silva Cimma abordó las materias internacionales durante ese período, y especialmente este caso $^{30}$. En este contexto, donde la palabra “democracia” adquiría visos taumatúrgicos y emergía como nuevo tótem unificador de la tribu, ciertos arranques de idealismo no sólo eran dables de esperar, sino que hasta deseables para el círculo decisor aylwinista. Para éste parecía necesario enviar mensajes de inclusividad y generosidad a la sociedad, y ello con la mayor frecuencia posible. Por lo tanto, el caso Honecker fue visto inicialmente como un problema interesante donde aplicar esta nueva lógica. Era un caso digno de ser aprovechado para ofrecer un "testimonio de nueva moralidad”.

Sin embargo, muy pronto se comprendió que se trataba de un asunto complejo in extremis, donde las variables domésticas y las estrictamente internacionales eran tan tenues como sinuosas. Era un asunto que confrontaba inevitablemente magnitudes diversas de estados y sociedades, pero sobre todo era un asunto donde impactaban con toda su fuerza las nuevas

\footnotetext{
${ }^{30}$ Muy ilustrativas son las declaraciones de Silva Cimma en entrevista dada a
} Raquel Correa (1992). 
configuraciones de poder internacional. Honecker pasó a representar la utopía eclipsada.

Por lo señalado ut supra, las dudas, tensiones y temores fueron decantando a medida que pasaban los días. El círculo decisor aylwinista se comenzó a percatar de que la coyuntura no estaba disponible para aceptar arranques de voluntarismo testimonial o impulsos idealistas. Es entonces cuando Aylwin y su canciller Silva Cimma toman conciencia de que su única opción es recurrir a todas sus destrezas y conocimientos jurídicos e imponer el criterio - lógico y evidente- de que otorgar asilo a Honecker, pese a constituir un mensaje halagador para la audiencia izquierdista, estaba produciendo un enojo real en las potencias centrales, lo que podría provocar un serio daño a la política exterior de Chile y especialmente a la tarea pendiente de identificar los nuevos imperativos estratégicos del Chile democrático; se debía diseñar una exit strategy de manera urgente.

El primer paso fue maniobrar sutilmente para no aparecer ante la opinión pública cediendo a las presiones alemanas y rusas ${ }^{31}$. Segundo, remover al embajador Almeyda sin provocar fisuras con el Partido Socialista. Tercero, designar un embajador especial (al eximio diplomático James Holger) en reemplazo de Almeyda, así como también un emisario especial, esta vez ante Alemania, para evitar daños al prestigio de Chile y a su alta capacidad de diálogo e interacción en el plano externo alcanzada tras la restauración democrática, misión encomendada a Roberto Cifuentes. Finalmente, abrirse a lo inevitable, entregar a Honecker a la justicia alemana y sólo a partir de ese momento mostrarse generoso y ofrecer cobijo a Honecker y su familia en este territorio alejado de las turbulencias post Guerra Fría. Aylwin y Silva Cimma abordaron así uno de los problemas más singulares que haya resuelto la diplomacia chilena, de profundísima naturaleza interméstica.

Sintetizando, el caso Honecker corroboró el aserto realista de que los impulsos idealistas, que en ciertos momentos puede exhibir una política

${ }^{31}$ Desde marzo de 1990, la situación de Honecker comenzó a ser monitoreada por diversos órganos estatales de la RFA. Especial preocupación despertó en el círculo decisor germanooccidental el apoyo que le prestaban funcionarios civiles y militares soviéticos. Luego, el subrepticio traslado a Moscú llevó al gobierno de Kohl a intervenir para evitar que Honecker escapase a la acción de la justicia. Desde septiembre de 1991, el ministro de Justicia, Klaus Kinkel, intentó persuadir a las autoridades de Moscú para que entregasen a Honecker y formalizó un pedido de extradición. La irritación de Bonn con Chile se debió básicamente a que el embajador Almeyda intervino justo cuando el gobierno de Kohl había alcanzado un acuerdo con las nuevas autoridades rusas (meses de noviembre y diciembre de 1991). Chile se convirtió, así, en un elemento tan sorpresivo como perturbador en las nacientes relaciones entre la Federación Rusa y la Alemania unificada (ver cronología en recuadro). 
exterior, son en esencia efímeros y obedecen a situaciones coyunturales que vive un círculo decisor determinado. En tal sentido, el caso Honecker podría ilustrar la premisa de Fareed Zakharia, uno de los más reconocidos pensadores realistas de la actualidad, en orden a que los principales actores internacionales no son los Estados sino quienes los representan, es decir los gobernantes. Son ellos los que por las razones más diversas ofrecen, a veces, ejemplos de arrebatos idealistas en la ejecución de una política exterior. Pero como bien apunta Kenneth Waltz —la voz profunda del neorrealismo - , la estructura internacional obliga a los Estados (o sea a los gobernantes) a no olvidar que en política internacional la ultima ratio es el poder, y nada más que el poder, lo que deja a las veleidades idealistas, como ocurrió con el caso Honecker, un espacio mínimo y por lo general intrascendente.

\section{Síntesis cronológica del caso Chile-Honecker}

7.10.1989: Pese a las sucesivas manifestaciones que bajo el lema "Nosotros somos el pueblo" (Wir sind das Volk) habían comenzado tímidamente en Leipzig y que en los días previos se habían extendido a Berlín oriental, Honecker festeja el aniversario 40 de la RDA en el Palast der Republik. Entre sus invitados especiales figuran Volodia Teitelboim, Luis Corvalán y Clodomiro Almeyda.

18.10.1989: En medio de multitudinarias manifestaciones contra el régimen, Honecker es destituido de todos sus cargos.

25.10.1989: Turbas de manifestantes asaltan el barrio Wandlitz donde vive Honecker; junto a su esposa Margot logra huir, aunque durante varios días se desconoce su paradero. Su hija Sonia emigra a Chile junto a su marido Leonardo Yánez y Roberto, el hijo de ambos.

8.12.1989: La Fiscalía de la RDA acusa a Honecker de corrupción, abuso de poder y alta traición.

9.01.1990: Tras una operación en el hospital berlinés Charité, Honecker es arrestado y recluido en la cárcel de Rummelsburg. Se le deja en libertad por "incapacidad para enfrentar un juicio" (Haftunfähigkeit).

3.4.1990: Honecker ingresa en busca de asilo al hospital militar de las fuerzas armadas soviéticas acantonadas en Beelitz; más tarde, por decisión del comandante general de las tropas soviéticas estacionadas en Alemania oriental, general Boris Snetkov, es trasladado subrepticiamente a Moscú, pese a protestas del gobierno de Bonn.

1.12.1990: La justicia de Berlín emite una orden de captura.

14.3.1991: El gobierno de Kohl entrega a la URSS una petición de extradición de Honecker.

15.4.1991: Volodia Teitelboim visita al matrimonio Honecker en el hospital militar donde se encuentran internados. 
28.5.1991: El matrimonio Honecker es trasladado a una casa de campo del gobierno soviético en las afueras de Moscú, donde ambos permanecen bajo arresto domiciliario.

4.9.1991: Llega a Moscú el ministro de Justicia de Alemania federal, Klaus Kinkel, a tratar con las autoridades rusas el caso Honecker.

4.11.1991: El Ministerio de Relaciones Exteriores ruso le informa al matrimonio Honecker sobre la petición alemana de extradición y le notifica que su subrepticio traslado a Moscú (13.2.1991) constituyó un acto de violación de la soberanía soviética. Las autoridades soviéticas le solicitan que retorne voluntariamente a Alemania. Honecker se niega.

1.12.1991: La prensa alemana informa que el embajador chileno en Moscú, Clodomiro Almeyda, se reúne con los Honecker con cierta periodicidad para verificar posibilidades de trasladarse a Chile. Gobierno chileno informa que para su ingreso a territorio nacional Honecker necesita pasaporte alemán.

Partido Socialista chileno expresa reservadamente al gobierno su preocupación por destino de Honecker.

3.12.1991: El subsecretario de Relaciones Exteriores de Chile, Edmundo Vargas, declara que Chile no está en condiciones de ofrecer asilo a Honecker. 8.12.1991: Embajador Almeyda llega a Santiago llamado por la Cancillería a informar sobre "situación política en Moscú”. Trasciende la preocupación del gobierno por reuniones sostenidas por él con Honecker en días previos.

10.12.1991: Los ministros de Justicia e Interior soviéticos y el Viceministro de Relaciones Exteriores de la Federación Rusa informan a Honecker de la orden de expulsión en un lapso de tres días.

11.12.1991: Se produce el ingreso de los Honecker a embajada chilena. Según versión de Margot Honecker, ella y su marido asisten a una cena a la residencia del embajador chileno en Moscú, Clodomiro Almeyda, cumpliendo una invitación formulada días antes, durante la cual su marido sufre un ataque al corazón. Su versión añade que Almeyda habría informado inmediatamente al gobierno chileno, el cual habría resuelto acogerlos temporalmente en calidad de "huéspedes".

12.12.1991: Margot Honecker acude a las embajadas de Corea del Norte y Siria en Moscú solicitando asilo; ambos países contestan positivamente pero las autoridades rusas reiteran la prioridad de la petición alemana. Los Honecker deciden permanecer por tiempo indefinido en la legación chilena.

Los partidos políticos chilenos toman postura ante la situación: la UDI critica accionar del embajador Almeyda y se opone al otorgamiento de asilo; PS y PC solicitan otorgar asilo inmediato y anuncian campaña en tal sentido, todos los demás partidos manifiestan opiniones divididas.

13.12.1991: Aterriza en Moscú un avión del gobierno de Pyongyang para trasladar a Honecker al país asiático. Embajada norcoreana en Moscú pide los salvoconductos correspondientes. En declaración pública, los ministerios del Interior y de Relaciones Exteriores de Chile afirman que se ha decidido que Honecker permanezca en la embajada chilena en Moscú "hasta encontrar una solución satisfactoria al problema”. El embajador alemán en Santiago, Wiegand Pabsch, declara que la actitud chilena respecto a Honecker es "lamentable y preocupante" y pide oficialmente que "haga salir" a Honecker 
de la embajada. Klaus Kinkel señala que Alemania consideraría "un acto hostil" que Chile brinde asilo a Honecker. Almeyda, en Santiago, insiste en la necesidad de otorgar asilo a Honecker.

14.12.1991: Presidente Aylwin se manifiesta conforme con otorgamiento de calidad de huésped, pero descarta brindar asilo. El ministro Secretario General de Gobierno, Enrique Correa, niega que Chile esté sufriendo presiones de Alemania o Rusia. En declaración oficial, Erich Honecker indica que sólo pretende buscar visa de ingreso a Chile. Abogado de Honecker, Wolfgang Ziegler, anuncia que su cliente no volverá voluntariamente a Alemania. Ministerio de Justicia alemán confirma que hay orden de captura internacional y que será detenido apenas pise suelo alemán. Canciller ruso, Andrei Kozyrev, declara que la aceptación de la oferta norcoreana es la mejor solución a la impasse creada en torno a Honecker.

15.12.1991: Chile envía a Moscú a James Holger, en calidad de embajador especial, y al político DC Roberto Cifuentes como "emisario especial” ante el gobierno alemán. El embajador Almeyda se mantiene oficialmente en funciones, pero permanece en Santiago por petición expresa del Presidente Aylwin "haciendo uso de sus vacaciones"; comienzan especulaciones de que será removido de su cargo.

18.12.1991: El subsecretario de RR.EE., Edmundo Vargas, declara que la situación de Honecker “depende de Rusia, que lo deje abandonar el país con el destino que él prefiera”. La agencia TASS informa que según el Presidente soviético Mijaíl Gorbachov, "Honecker saldrá próximamente para Corea del Norte”. El ministro ruso de Justicia Nikolai Fyodorov declara al Komsolmskaya Pravda que si Corea del Norte le entrega a Honecker pasaporte diplomático, éste puede abandonar Moscú, en caso contrario será arrestado.

19.12.1991: Embajador norcoreano en Berlín Yin Yong Pak aclara que su país está dispuesto a asilar a Honecker por razones humanitarias, pero que no ha considerado otorgarle un pasaporte diplomático.

28.12.1991: En declaraciones al Berliner Kurier, Margot Honecker dice confiar en que podrán recibir atención médica en Pyongyang y luego asilarse en Cuba. "No obstante — agrega — el mejor regalo sería pasar Navidad con nuestros amigos en Chile."

14.2.1992: Ante deterioro de salud de Honecker, gobierno alemán informa que acepta que sea trasladado a un hospital moscovita. Éste se niega a salir de la embajada sin declaración expresa sobre inmunidad. Personal de la embajada chilena debe hacer esfuerzos para convencerlo de la necesidad de que salga de la embajada rumbo a un hospital en las condiciones establecidas por Alemania.

19.2.1992: El viceministro de Relaciones Exteriores de Chile, Edmundo Vargas, declara que Honecker puede viajar a Chile, si Rusia acepta.

20.2.1992: Presidente Aylwin confirma “gestiones personales” para solucionar caso Honecker, aunque se abstiene de entregar detalles.

24.2.1992: Tras intensas negociaciones entre Chile, Rusia y Alemania y escoltado por policías rusos, Honecker sale de embajada chilena rumbo a la clínica Botkin. A su salida hace un gesto demostrativo levantando su puño derecho; la imagen es captada por los principales medios de prensa. 
3.3.1992: Honecker abandona la clínica Botkin y regresa a la embajada chilena. 10.3.1992: El gobierno chileno confirma que el matrimonio permanece en la legación diplomática con el estatus de "huéspedes". Autoridades rusas deciden reforzar visiblemente guardia en torno al edificio.

1.4.1992: Embajador Almeyda cesa definitivamente su responsabilidad al frente de la legación chilena; su salida se produce manteniendo una estricta reserva. Holger asume titularidad en embajada.

3.6.1992: Los tribunales de Berlín inician proceso contra Honecker según lineamientos de la fiscalía de noviembre de 1990.

29.7.1992: Autoridades del Ministerio de Relaciones Exteriores de Rusia reciben a Honecker de manos del embajador James Holger, siendo trasladado inmediatamente al aeropuerto Sheremetyevo, desde donde es conducido en un avión especial hacia Berlín-Tegel. En horas de la tarde Honecker es ingresado a la cárcel JVA de Alt-Moabit, Berlín, con el prontuario No 2955-92. Se le acusa de 49 asesinatos en la frontera y desvío de fondos públicos. Margot Honecker viaja a Chile. Según versión de Corvalán, tras el acuerdo con el gobierno ruso, el embajador Holger le dio diez minutos para abandonar el edificio de la embajada.

16.8.1992: Informe médico final establece que Honecker padece cáncer hepático y es desahuciado, estimando los médicos tratantes que le quedan cerca de 18 meses de vida.

1.8.1992: Gladys Marín lo visita en la cárcel de Moabit.

23.12.1992: Se le informa que será puesto en libertad en las próximas semanas y se le extiende pasaporte.

9.1.1993: Socialistas y comunistas que residieron en la RDA anuncian que “ante la inminente liberación” de Honecker han formado un Comité de Solidaridad con Erich Honecker con una cuenta bancaria para reunirle dinero; lo encabeza la abogada Graciela Álvarez. Semanas antes un antiguo amigo de Honecker, Hans Wauer, forma en Berlin el Solidaritätskomittee Erich Honecker.

10.1.1993: El subsecretario del Interior Belisario Velasco informa que Honecker puede ingresar a Chile sin problemas. Pese a insistentes rumores de prensa, niega que el gobierno vaya a financiarle tratamiento médico en Chile. 13.1.1993: Luego de un proceso que dura 169 días, la justicia alemana anuncia que Honecker por razones de edad será eximido de sus responsabilidades penales. Por la noche es conducido al aeropuerto de Tegel en Berlín para ser embarcado rumbo a Chile.

14.1.1993: Honecker despega a Santiago de Chile. A su llegada es internado en la Clínica Las Condes. Posteriormente se instala en su domicilio particular en el barrio La Reina de Santiago, donde escribe sus memorias.

8.2.1993: Bild am Sonntag informa detalladamente de la vida cotidiana de Honecker en Santiago.

13.4.1993: El caso Honecker es declarado cerrado por la justicia alemana.

29.5.1994: Honecker muere a la edad de 81 años producto de un ataque al corazón. La semana anterior había rechazado someterse a una nueva operación y los médicos tratantes lo habían declarado desahuciado. Su cadáver es cremado en el Cementerio General. Sus cenizas las mantiene en custodia su esposa Margot en su domicilio de Santiago, aunque no existen impedimentos legales para ser transportadas de regreso a Alemania. Semanas antes de 
fallecer publicó sus memorias bajo el título Moabiter Notizen (Apuntes de Moabit) en la editorial Das Neue Berlin.

8.10.2002: La revista Focus publica dos cartas de Margot Honecker a su hermano Manfred y hermana Edith donde queda en evidencia que el matrimonio logró hacer transferencias de millonarias sumas de dinero hacia Chile. Las cartas fueron halladas en dos maletas del matrimonio abandonadas antes de ingresar al hospital militar soviético en Beelitz.

22.10.2002: La revista de reportajes Exakt publica un artículo firmado por Birgit Mittwoch en que informa que el martillero público (y antiguo militante comunista en Berlín occidental) Karl-Heinz Kaiser organizó entre 1994 y 1995 dos remates con objetos personales de Honecker donde habría reunido más de 400 mil marcos que se los envió paulatinamente y por mano a través de un ex músico de la RDA, Reinhold Andert, hacia Chile.

18.5.2005: La prensa alemana informa que el "Ostseeland", el antiguo yate de Honecker (confiscado tras su caída en desgracia y vendido a una sociedad maltesa) se encuentra semiabandonado y en venta en Estambul.

Fuentes: Información aparecida en El Mercurio (Chile), La Segunda (Chile), Qué Pasa (Chile), Der Spiegel (Alemania), Die Zeit (Alemania) y Focus (Alemania).

\section{BIBLIOGRAFÍA}

Almeyda, Clodomiro: Reencuentro con mi Vida. Santiago: Ediciones del Ornitorrinco, 1987.

Bedürftig, Friedemann: Lexikon Deutschland nach 1945. Hamburg: Carlsen, 1996.

Chrenko, Helma y Reinhold Friedman: Declaraciones en entrevista dada a Ivan Witker. En “Estamos Dispuestos a Aprender del Capitalismo”, El Diario, 3 de noviembre de 1989, Santiago.

Corvalán, Luis: De lo Vivido y lo Peleado. Memorias. Santiago. LOM, 1997.

La Otra Alemania, la RDA. Conversaciones con Margot Honecker. Santiago: ICAL, 2000.

El Derrumbe del Poder Soviético. Santiago: Los Andes, 1993.

Evans, Graham y Jeffrey Newnham: Dictionary of International Relations. Londres: Penguin, 1990.

Hofmeister, Wilhelm: Die Deutschen Christdemokraten und Chile. En KAS-AI No 4 (2004), pp. 22-49, Konrad-Adenauer-Stiftung, Berlín.

Kagan, Donald: Sobre las Causas de las Guerras y la Preservación de la Paz. Madrid: FCE, 2003.

Krämer, Raimund: "De una Diplomacia Desaparecida. La Política Exterior de la República Democrática Alemana y sus Relaciones con América Latina”. En Estudios Internacionales, Vol. 28, No 110, IEI, Universidad de Chile, Santiago, 1995.

"Die ganz andere Beziehung. Chile und die DDR". En Freitag 39 (19.9.2003). www.freitag39.de

Kunze, Thomas: Staatschef a.D. Die letzten Jahren des Erich Honecker. Berlin: Links Christoph Verlag, 2001. 
Möbus, Karlheinz: "Wie ein Potsdamer Plattenbau zum Zufluchtsort vor Pinochet Wurde”. En Welt am Sonntag, 22 de enero de 2006.

Nye, Joseph: La Paradoja del Poder Norteamericano. Madrid: Taurus, 2003.

Ortega, Javier: “La Inédita Historia de los Años Verde Olivo en la Mira de la Stasi”. En La Tercera, 6 de mayo, 2001, Santiago.

Puccio Giesen, Osvaldo: Un Cuarto de Siglo con Allende. Santiago: Emisión, 1985.

Roewer, Helmut, Stefan Schäfer y Matthias Uhl: Lexikon der Geheimdienste im 20. Jahrhundert. München: Herbig, 2003.

Sieber, Malte: “Lobrede auf ein verlorenes Paradies”. Berlin: Tagesspiegel, 2000.

Silva Cima, Enrique: Declaraciones en entrevista dada a Raquel Correa. En "Honecker... ¿De Huésped a Turista”. En El Mercurio, 12 de enero de 1921.

Widmann, Carlos: “Die Erbin Pinochets”. En Cicero, noviembre, 2005.

Wilhelmy, Manfred, y Roberto Durán: "Los Principales Rasgos de la Política Exterior Chilena entre 1973 y el 2000”. En Revista Ciencia Política, Vol. 23 № 2, pp. 273-286, Santiago.

Witker, Ivan: Relaciones América Latina-República Democrática Alemana. Principios, Antecedentes y Perspectivas. Documentos de trabajo, Programa de Seguimiento de Políticas Exteriores Latinoamericanas (PROSPEL), Santiago, diciembre, 1988.

"La Política Exterior de Chile frente a la Teoría de las Relaciones Internacionales 1990-1999”. En Bicentenario, Revista de Historia de Chile y América, Vol. IV No 1 (2005), Centro de Estudios del Bicentenario, Santiago.

Wolf, Markus (con Anne Mc Elvoy): El Hombre Sin Rostro. Buenos Aires: Javier Vergara Editor, 1997. 